\title{
The Volatility Effect of Single-Stock Futures Trading on the Pakistani Stock Market
}

\author{
Adil Awan* and Amir Rafique**
}

\begin{abstract}
The impact of single-stock futures on spot market volatility is still debated in the finance literature. The aim of this study is to analyze the effect of the introduction of single-stock futures on the volatility of the Karachi Stock Exchange (KSE). We examine changes in the level of volatility and structure after the introduction of single-stock futures, evaluating 24 companies listed on the KSE. The study applies the F-test to determine differences in variance as a traditional measure for volatility and uses GARCH $(1,1)$ as an econometric technique for detecting time-varying volatility. The results show that there is no effect on the volatility level but that changes occur in the structure of volatility after stock futures trading.
\end{abstract}

Keywords: Single-stock futures, derivatives, volatility.

JEL classification: $610,613,617$

\section{Introduction}

Stock market volatility has been a vital area of research for the last three decades. Volatility is a risk measure and is widely used in finance studies, given researchers' wide interest in risk assessments of securities or markets. There has been extensive debate on derivatives trading (index futures and index options) and its impact on the underlying spot market. The general perception about derivatives is that they increase stock prices but there is no consensus due to the mixed empirical evidence.

The impact of the introduction of derivatives securities (futures and options) on the underlying spot market is a less researched area, but there is little consensus among researchers and practitioners on this issue. Given the differences in theoretical frameworks and empirical findings, there is no unanimous conclusion that futures trading stabilizes or destabilizes the spot market.

\footnotetext{
* The author is a postgraduate student at the Faculty of Management Sciences at SZABIST, Islamabad (email: adilawan329@gmail.com).

** The author is an assistant professor at the Faculty of Management Sciences at SZABIST, Islamabad.
} 
Future contracts are introduced into the stock market to manage and minimize risk in the underlying spot market. Single-stock futures (SSFs) are contracts that are traded on stock exchanges; they represent future commitments to buy or sell shares (of any specific listed company) at a fixed rate. SSFs are derivatives and their price depends on ordinary shares. As these contracts expire, the holder buys at a predetermined price from the seller. This type of physical delivery contract is called a deliverable futures contract. The determination of gain or loss is done on the expiration of the contract. The difference between the spot and futures price is the actual gain or loss of the contract. Cash-settled futures contracts are also now available in which the daily settlement of contracts is carried out by a stock exchange.

The link between the spot and futures market can be explained by the cost-of-carry concept, which Strong (2005) defines as the "net cost incurred for carrying an asset forward in time." There are two types of net costs: carrying returns (dividends) and carrying charges (interest). The fair value of a futures contract is determined by the spot price of the underlying asset and the cost of carry. The futures contract price is a function of and dependent on the underlying spot price. It is plausible that a reciprocal relation exists between the two markets.

The introduction of SSFs provides an opportunity to reinvestigate futures trading comprehensively. Stock futures offer a direct assessment of the probable impact on underlying shares. The market-wide impact of futures trading can be assessed through index futures, whereas a company-wide impact can be assessed through SSFs.

\section{Contextual Analysis}

The Pakistani stock market comprises three stock exchanges, of which the Karachi Stock Exchange (KSE) is the largest and oldest; it is also the most liquid and active exchange in Pakistan. The KSE was established in 1947 and provides products such as ready market, index futures, and stock futures. Trading in stock futures started on 1 July 2001 and index futures started on 1 April 2008. The Pakistani stock market has faced many problems in development, as have other developing countries. In the last few years, the KSE has witnessed extraordinary volatility and is considered one of the most volatile markets in the world. Stock futures trading in Pakistan began with ten companies in 2001 and increased to 46 companies in 2008 (Khan, Shah, \& Abbas, 2011). 


\subsection{Significance of the Study}

Traditionally, futures markets are considered more volatile than spot markets. The close link between the two markets creates the possibility of risk transfer from one to the other. The literature has documented both increases and decreases in volatility, with some studies presenting mixed results. This lack of consensus means that further research is necessary. Specifically, SSFs in Pakistan have received little attention.

This study aims to fill this gap in the literature. Existing studies on the volatility effect of SSFs on the underlying spot market tend to focus on developed countries, with few studies having been conducted on a developing country such as Pakistan. Thus, we aim to add a developing country perspective to this area of research. Additionally, we analyze company-wide impacts rather than market-wide impacts, and so present a direct evaluation of the possible effects. The study's results could prove useful to various stakeholders, such as practitioners, academics, investors, and regulators.

\subsection{Problem Statement}

Futures markets are considered more volatile than spot markets, and thus can be a source of volatility for spot markets as futures trading can increase volatility in the underlying spot market. Research is needed to investigate comprehensively whether stock futures increase or decrease spot market volatility, especially in the context of Pakistan.

\subsection{Aim of the Research}

Our aim is to determine the impact of introducing SSFs on the volatility of securities. Specifically, we intend to:

1. Study changes in the volatility level after the introduction of SSF trading in Pakistan

2. Investigate changes in the volatility structure after SSF trading in Pakistan

\subsection{Study Delimitations}

This study investigates only the Pakistani context. The sample firms were included on the basis of the data available. The study spans the period 1 July 2001 to 31 December 2010. 


\section{Literature Review}

\subsection{Derivatives Markets}

Over the years, two views have emerged with respect to derivatives markets to clarify why derivatives trading can affect spot market volatility. This discussion has focused on arbitrage activities, which link the derivatives market with the spot market. These contrasting views depend on the assumptions regarding arbitrageurs. A key issue in derivatives trading is whether it brings informed or uninformed traders to the stock market. One view is pro-derivatives: it states that derivatives trading brings informed traders to the market and that these traders lead to greater efficiency and lower volatility in the underlying market. The second view is anti-derivatives: it holds that derivatives trading brings in speculators who are involved in massive and irrational speculative activities (Robbani \& Bhuyan, 2005).

Derivatives markets have several advantages over trading in spot markets. The main benefits are low transaction costs, high leverage, and greater liquidity. Futures trading allows investors market-wide exposure with low transaction exposure. Investors take large positions in futures trading compared to the spot market. The disadvantage of this high degree of leverage provided by futures trading is that it can attract uninformed traders or speculators to both markets, who may then increase the volatility of the underlying market for short-term profit. Futures markets are affected by speculation due to the low transaction costs involved. Uninformed traders or irrational speculators trading in futures can destabilize the underlying spot market-the destabilizing effect of the futures market.

Robbani and Bhuyan (2005) differentiate between informed and uninformed traders. Informed traders carry out arbitrage activities while uninformed traders are involved in speculative activities. An increase in informed traders will increase trading volumes and lead to lower volatility in the underlying spot market. This reflects the pro-derivatives

view or the stabilizing effect of futures trading, and holds if no trading volume is transferred to the futures market. If the trading volume is diverted, it can lead to low trading volumes and increased volatility in the spot market.

Faff and Hillier (2005) find that, given new financial innovations such as derivatives products, informed traders may be attracted to the 
futures market due to the low transaction costs and high leverage involved. Trading volumes are diverted to the futures market and lead to the destabilization of the spot market.

In their pioneering work on SSFs, Peat and McCorry (1997) present the opposite view to futures trading that leads to market stabilization or destabilization. They argue that, with the advent of stock futures, if the market moves toward stabilization or completion, there will be an increase in share prices, resulting in a low required rate of return, an increase in trading volume, and a decrease in spot market volatility. If the market is destabilized after the advent of stock futures, there will be a decrease in share prices, resulting in higher required returns, a decrease in trading volume due to the migration toward the futures market, and an increase in spot market volatility.

\subsection{Decreased Volatility Due to Futures Trading}

Elfakhani and Chaudhury (1995) study the effect of the introduction of options on the Canadian spot market. They note that both total and systematic risk decreased in the early 1970s due to options trading. In the late 1980s, near the time of the market crash of 1987, the systematic risk associated with the underlying individual equity shares increased due to the listing of options contracts. They conclude that options listing has a stabilizing effect on the underlying spot market, except in the case of the market crash of 1987.

Chatrath, Ramchander, and Song (1995) test the hypothesis that options trading increases spot market volatility in the US market. Their results show that, while options trading reduces volatility in the spot market, increased volatility in the spot market increases the volatility of options trading. Overall, options trading reduces risk in the underlying market. McKenzie, Brailsford, and Faff (2001) find a significant reduction in unconditional volatility and a decline in systematic risk. There is slower incorporation of information in prices, old news has a shorter impact, and the persistence of shocks has a smaller effect.

Bologna and Cavallo (2002) attempt to determine whether stock index futures contracts (SIFCs) reduce the volatility of the stock market. They observe a reduction in volatility and an increase in spot market efficiency. This is accompanied by a decrease in unconditional volatility. Their results show that new information is incorporated more rapidly in prices (more clustering) but that this impact does not last long (less 
persistence). The persistence of shocks (ARCH + GARCH term) also declines between the pre- and post-period, which supports the stabilizing hypothesis of futures trading.

Ang and Cheng (2005) investigate whether financial innovations can improve market efficiency. They test for market efficiency by applying the "specific announcement of news." If there are only a few excess unexplained post-listing price changes for SSF firms, then the market is deemed efficient. Their results show that the market becomes efficient after SSF trading. They attribute this efficiency to increased trading in the futures market, high leverage, and low transaction costs, which benefit arbitrageurs rather than speculators.

Mazouz and Bowe (2006) investigate the volatility effect of SSF contracts on the London stock exchange and find a reduction in unconditional volatility and systematic risk. With futures trading, current news is incorporated into prices more rapidly, while old news has a shorter impact and a lower shocks effect. Drimbetas, Sariannidis, and Porfiris (2007) report the effect of index futures contracts on the underlying equity market in Greece, using the FTSE/ASE-20 as the underlying index for the period 1997-2005. They adopt an exponential GARCH model for their volatility analysis and find a reduction in volatility post-futures trading with no change in the structure of volatility. However, unconditional volatility decreases after the introduction of futures.

De Beer (2008) investigates the SSF effect on the South African stock market. The volatility of the underlying equity market is reduced and there is no change in systematic risk. There is faster incorporation of fresh news, while old news has a shorter impact and smaller shocks effect.

Khan (2006) studies the impact of futures trading on spot volatility in Pakistan. His results show that the spot market leads the futures market in incorporating new information. The futures market is not responsible for volatility in the spot market. He concludes that volatility in the futures market is due to the outgrowth of the spot market. In a later study, Khan and Hijazi (2009) examine SSF trading and share price volatility in Pakistan and find a reduction in stock price volatility after the introduction of futures trading. However, there is a positive relation between spot volume and spot volatility, which supports the stabilizing effect of futures trading. 


\subsection{Increased Volatility Due to Futures Trading}

Peat and McCorry's (1997) study is one of the first empirical studies to look at the role of SSFs in the Australian spot market. They base their study on the existing literature concerning the impact of the introduction of options and SIFCs on the underlying equity market. They test the complete markets theory, the diminishing short sales theory, and the improved information environment hypothesis. Their results contradict earlier findings on the introduction of derivatives trading. Previous studies had argued that the market becomes complete after the introduction of derivatives trading. The introduction of options leads to a reported increase in price and volume but a decrease in volatility. They also argue that there is no effect on price but an increase in volume and volatility.

Smit and Nienaber (1997) look at futures trading activity and stock price volatility in South Africa (futures trading activity refers to volume and open interest on the stocks). Their regression analysis results show that greater activity in futures leads to more volatility in the underlying spot market. Swart (1998) examines the impact of index futures on the volatility and liquidity of the underlying Johannesburg Stock Exchange, and finds that the increase in volume and volatility is due to an increase in index futures trading.

Butterworth (2000) supports the argument that futures trading has changed the structure and level of volatility in the spot market. There is less volatility clustering but more volatility persistence in returns following the introduction of futures trading. There is a considerable increase in the constant term but a huge rise in the unconditional variance in the variance equation used. He concludes that futures have a beneficial effect on the spot market.

Faff and Hillier (2005) analyze complete markets, the improved information environment, and the diminishing short sales theory in the context of the introduction of options in the UK. They construct a sample of 86 companies involved in options trading over the period 1978-99. The price effect is tested using an event-study methodology. Abnormal returns are calculated using a market model. Positive abnormal returns arise with the introduction of options trading but there is no visible pattern over the sample period. The volume effect is estimated using dummy variable regression and indicates a rise in the level of trading volume, following the introduction of options trading. The volatility effect is also measured using dummy variable regression, and shows a rise in the level of volatility post-options trading. 
Bae, Kwon, and Park (2004) study the effect of futures trading on stock market efficiency and volatility in the Korean context. Their sample consists of the KOSPI-200 and a control sample over the period 1990-98. The authors use dummy variable regression to show the destabilizing effect on and increase in volatility of the underlying spot market. Aitken and Segara (2005) study the initiation impact of Australian warrants on the underlying individual equity shares. The returns on shares decline after the introduction of warrants, and both the volume and volatility of the spot market rises.

Ahmad, Shah, and Shah (2010) assess the impact of futures trading on spot price volatility in Pakistan. The returns show both clustering and persistence. They find that the KSE-100 predicts both the spot and futures markets. However, these markets do not Granger-cause each other or the market index. All the markets are found to be highly volatile, which is the reason for the increased volatility. Consequently, the authors support the destabilizing hypothesis of futures trading in contrast to previous studies on Pakistan.

\subsection{Mixed Evidence of Futures Trading}

Oehley (1995) investigates the impact of the introduction of SIFCs on the underlying market index in South Africa, but the study's results do not provide any evidence that futures trading increases volatility. The general increase in share market volatility is explained by the 1987 market crash.

Darrat and Rahman (1995) look at US evidence on futures trading and its impact on share price volatility. They report that futures trading does not increase the volatility of the underlying equity market. There is evidence of spike volatility in the sample period, but it is not attributed to futures trading. Instead, the authors attribute the volatility in stock prices to the over-the-counter index and term structure.

Parsons (1998) studies futures trading and its impact on the cash (spot) market in the context of South Africa. The results indicate no increase in the volatility of the underlying indexes, which supports the stabilizing effect of futures trading. Vanden Baviere and De Villiers (1997) examine stock price volatility after the introduction of index futures and find no evidence for its impact on the increased volatility of firms that constitute the market index. 
Lee and Tong (1998) analyze the emergence of individual stock futures (ISF) contracts in the Australian equity market. They report no associated increase in trading volumes and no effect on volatility, and suggest that the increase in volume is due to the greater participation of firms because futures trading has expanded investment opportunities and reduced risk. Dennis and Sim (1999) compute the impact on volatility of the introduction of ISF contracts on the Sydney Futures Exchange. Their findings show that trading in the spot market (rather than the futures market) has a large effect on spot market volatility. Consequently, ISF contracts have a minor effect on the volatility of the cash market.

Kruger (2000) looks at index futures and stock price volatility in South Africa, and suggests that futures trading does not increase the volatility of equity indices. As the date of expiration of a futures contract approaches, there is an increase in futures trading. Hung, Lee, and So (2003) examine the impact of SSF contracts listed on foreign stock exchanges on the underlying domestic equity markets. They find evidence that SSF contracts listed in foreign countries lead to increasing volatility in the underlying domestic equity market. Moreover, daily shocks to foreignlisted SSF firms increase the conditional volatility in their home underlying equity market. A reduction in conditional volatility is seen to be the result of a high variable and predictable activity across days. There are no differences in unconditional volatility between the pre- and post-futures period. There is slower incorporation of information in prices, and old news has a shorter impact and smaller shocks effect.

Using a GARCH model, Mazouz (2004) studies the effect of introducing equity options on the NYSE, but finds they have no effect on either unconditional or conditional volatility. Kumar and Mukhopadhyay (2004) examine the impact of futures trading on the underlying Indian equity market: index futures trading has no effect on the average and additional level of volatility. New information is incorporated in prices but old information and shock effects are less persistent.

Robbani and Bhuyan (2005) determine the volume and volatility effect of futures and options trading on the US stock market index. They investigate 30 companies that form part of the DJIA index over the period 1989 to 1994. Using the t-test, F-test, Wilcoxon signed rank test, Parkinson's estimator, and GARCH model for time-varying volatility, they find that the returns of all the underlying firms showed no effect as a result of derivatives trading. However, the trading volume of 23 companies increased post-derivatives trading. There was also an increase 
in conditional volatility post-futures and options trading, but no increase in unconditional volatility. There was faster incorporation of fresh news, while old news had a longer impact and greater shocks effect.

Chau, Holmes, and Paudyal (2005) study the impact of crossborder and domestic listing of SSF contracts on underlying market volatility and feedback trading in the UK. They report an improvement in market efficiency, reduced volatility in the underlying market, and a small decrease in the level of feedback trading. They are obvious differences among industries in terms of market dynamics. The positive impact on the underlying market from the pre- to post-futures period is not related to futures trading. A constant component is used to model the serial autocorrelation present in the possible market inefficiency; the improvement in efficiency is due to a reduction in this component.

Clarke, Gannon, and Vinning (2007) analyze the introduction of warrants in the Australian stock market and find no subsequent difference in volatility. Khan et al. (2011) look at SSF trading and its impact on stock prices. Both traditional and econometric analyses yield mixed results. The GJR-GARCH analysis shows a limited and fractional decrease in volatility both for SSF firms and the control sample. Thus, this partial reduction can be attributed to other market-wide factors but not to futures trading.

The majority of existing studies suggest, therefore, that derivatives trading has no effect on the volatility of the underlying spot market. Most SSF studies focus on the US, UK, Australia, and South Africa and find mixed evidence for volatility. Previous research on derivatives trading (warrants, options, and SIFCs) also yields varied and indecisive results. In Pakistan, most studies have focused on futures trading and only some on SSFs. Generally, however, there is no conclusive study on futures trading.

\section{Theoretical Framework}

The complete markets hypothesis, diminishing short sales restrictions hypothesis, and improved information environment hypothesis (see Ross, 1977; Miller, 1977; Detemple \& Seldon, 1991; Figlewski \& Webb, 1993) all provide a conceptual framework for determining the impact of options on the underlying spot market.

The theory of complete markets (Ross, 1977; Arditti \& John, 1980) holds that the introduction of options increases opportunities for investors in terms of risk/return patterns. Options provide favorable and 
attractive positions for investors. Expanding and improving the opportunity set increases the demand for shares and, as a result, increases equilibrium prices.

Under the diminishing short sales theory, the introduction of options can complete markets by allowing short positions. These synthetic short positions allow investors who have a negative view of shares to trade based on information they were not allowed to share previously in the absence of options. Informational efficiency is restricted by short-sales constraints and negative information cannot be incorporated into prices (Miller, 1977). In this situation, only optimistic investors will buy shares, leading to an imbalance in supply and demand and an increase in equilibrium prices. This imbalance is corrected through arbitrage and there is a decrease in prices.

The improved information environment hypothesis comprises several dimensions, one of which opposes the short-sales hypothesis, stating that informed traders with negative information will trade and earn profits from their better information. Another dimension states that the introduction of derivatives trading increases analysts' and media coverage, changing the investment mix (insider traders, speculators, uninformed traders) in underlying stock.

The vast majority of studies on the impact of derivatives trading on the underlying equity market are based on futures, with few focusing on the introduction of SSF trading. Most studies on derivatives trading and their impact on the underlying spot market are based on options. Both SSFs and options belong to the same category of derivatives and have similar characteristics but with different patterns of returns and leverage; we assume these theories to hold for both.

\section{Research Methodology}

\subsection{Data and Sample}

Our sample was filtered based on the following criteria: (i) any SSFs delisted during the sample period were excluded from the analysis, and (ii) a stock must have 500 days of spot price data both pre- and postevent. The sample period of analysis was based on previous studies, where it ranged from three months to three years. To avoid any bias, we selected two-year pre- and post-event data for SSFs. 
Trading in ISFs on the KSE commenced in July 2001. The study's sample period begins on 1 July 2000 and ends in December 2010. Khan et al. (2011) use data on 46 single-stock firms, ending in June 2008. We have selected 24 firms for our study. The daily closing share prices were obtained from the KSE's online database for a period of one year prior to a year after the listing of each stock. This yielded more than 500 daily observations per stock for each of the subperiods.

\subsection{Hypothesis}

The study is based on the following hypotheses:

- H0: The introduction of SSFs has no impact on the underlying volatility.

- H1A: The introduction of SSFs has either a positive or negative impact on the underlying volatility.

\subsection{Data Analysis Techniques}

\subsubsection{Calculation of Returns}

We use the following formula to calculate the returns on each stock:

$$
R_{i t}=\ln \left(\frac{P_{t}}{P_{t-1}}\right)
$$

where $R_{i t}$ is the return on security $i$ in period $t, P_{t}$ is the closing price of security $i$ on day $t$, and $P_{t-1}$ is the closing price of security $i$ on the day $t-1$.

\subsubsection{Volatility Effect}

Volatility is a statistical measure used to capture the tendency of a security or market to rise or fall sharply over a period of time. It is widely used in finance studies as a proxy for assessing the risk of any security or market. Volatility is measured in standard deviations, as a variance, or beta. According to the framework provided by major theories, the probable effect of stock futures trading on the underlying spot market is as follows:

\begin{tabular}{llll}
\hline & \multicolumn{3}{c}{ Expected change in underlying spot market } \\
Characteristic & $\begin{array}{l}\text { Complete } \\
\text { markets theory }\end{array}$ & Diminishing short & Improved information \\
Volatility & Lower & Lower & environment hypothesis \\
\hline
\end{tabular}

Source: Clarke, Gannon, and Vinning (2007). 
We first apply the F-test for differences in variance in a preliminary investigation of volatility. We then use a generalized autoregressive conditional heteroskedastic (GARCH) model to capture the changes in conditional volatility.

\subsubsection{F-Test of Difference in Variance}

Variance is a measure of volatility. The larger the variance among returns, the higher will be the volatility and the riskier the security or market. It is calculated as the mean sum of squares of the difference between the values and means of a securities sample. The F-test is a traditional measure used to examine changes in volatility (unconditional variances). It is applied to the ratio of pre-SSFs versus post-SSFs.

$$
\text { F-test }=\frac{S_{1}^{2}}{S_{2}^{2}} S_{1}^{2}=\text { pre-event variance } S_{2}^{2}=\text { post-event variance }
$$

\subsection{Autoregressive Conditional Heteroskedasticity (ARCH)}

The assumptions of OLS regression are: the expected value of the residuals will be zero, constant variance of residual terms, and no autocorrelation in the data series. The constant variance assumption (error terms) is also known as homoskedasticity. The basis of ARCH/GARCH modeling is the violation of the homoskedasticity assumption. The ARCH effect occurs in time series that do not have a constant variance (heteroskedastic).

$\mathrm{ARCH}$ is a condition in which the variance of the error terms in one period is dependent on the variance of the error terms in the previous period. In this situation, the hypothesis test of regression coefficients and their standard errors will be invalid. ARCH/GARCH modeling does not consider heteroskedasticity a problem to be corrected; rather, it includes the variance in the model (Engle, 2001). ARCH/GARCH models correct any OLS deficiencies by meeting the required assumptions. GARCH models have a constant unconditional variance, and are conditionally heteroskedastic and mean reverting.

Engle's (1982) ARCH models are designed particularly for modeling and forecasting conditional volatility; later, Bollerslev (1986) introduced the GARCH model. In the ARCH model, the dependent variable's variance is included as a function of the independent variable and its past values. In the GARCH $(p, q)$ model, conditional volatility (variance) is a function of the lagged terms of conditional variance and past squared error terms. 
Engle (2001) states that the standard $\operatorname{GARCH}(p, q)$ has two standard terms. The first term $(p)$ indicates the number of $\mathrm{ARCH}$ terms (autoregressive lags included in the model) and the second term $(q)$ indicates the GARCH terms (number of moving average lags). GARCH $(1,1)$ refers to first-order ARCH and GARCH terms. GARCH models also capture volatility clustering, which, according to Engle (1993), represents high volatility followed by more tranquil periods of low volatility.

\subsection{GARCH $(1,1)$ Model}

The basic GARCH $(1,1)$ specification (mean equation) is as follows:

$$
y_{t}=\alpha+\beta y_{t-1}+\varepsilon_{t} \ldots \varepsilon_{t}\left(o, h_{t}\right)
$$

where $y_{t}$ is the return on the security, $\alpha$ is a constant, $\beta y_{t-1}$ is the autoregressive coefficient and explanatory (lagged) variable, and $\varepsilon_{t}$ is the residual term.

The variance equation is written as:

$$
h_{t}=\omega+\alpha \varepsilon_{t-1}^{2}+\beta h_{t-1} \ldots \omega>0, \alpha>0, \beta \geq 0
$$

The unconditional constant variance of the error term is $\operatorname{var}\left(\varepsilon_{t}\right)=\frac{\omega}{1-\alpha-\beta}$

$h_{t}$ is the conditional variance in period $t, \omega$ is a constant (longterm average), $\alpha \varepsilon_{t-1}^{2}$ is the news coefficient, and the ARCH (1) term $\beta h_{t-1}$ is the persistence coefficient (old news and GARCH (1) term). The variance equation consists of three terms: a constant $(\omega)$, information on previous-period volatility (ARCH term), and the forecasted variance of the last period (GARCH term).

Current asset price is explained by the autoregressive component of the mean equation. In the variance equation, the error terms are modeled as time varying rather than constant. The parameters of GARCH $(1,1)$ show that current volatility is a function of past squared error terms and an autoregressive component of the conditional variance. Engle (2001) states that, for a mean-reverting variance process, the parameters estimated from the GARCH model should be positive and their value should not be greater than 1 . 
De Beer (2008) argues that the GARCH equation has two main effects: the impact of recent information on the market (ARCH effect) and that of old information on the market (GARCH effect). It is important, statistically, to know whether recent news is more important than old news. Current and lasting impacts are measured by changes in the size of the $\mathrm{ARCH}$ and GARCH effects. Volatility persistence can be measured by adding the two effects. A sample will exhibit volatility clustering and persistence if both the $\mathrm{ARCH}$ and $\mathrm{GARCH}$ terms are significant. This clustering and persistency process shows that, if there is a shock to stock prices, it will persist for many successive periods. A shock to share prices will last for a short period if the ARCH and GARCH terms are insignificant.

In the same way, an increase (decrease) in ARCH (1) from the preevent subsample to the post-event sample will be associated with faster (slower) dissemination of information (news) on the stock prices. If there is an increase (decrease) in GARCH (1) from the pre-event subsample to the post-event sample, then old news will have a long-lasting effect on share prices. The autoregressive root, which is the sum of the ARCH and GARCH values, represents the tendency of specific stock to reflect the impact of the shock in its price. The root shows the persistence of shocks.

The ARCH (1) and GARCH (1) effects are tested separately for the pre-event and post-event subsamples. Changes in the unconditional variance can be measured by introducing a dummy variable into the conditional variance equation. The dummy variable for the pre-event is 0 and for the post-event is 1 . Futures trading will increase (decrease) volatility if there is a significant positive (negative) dummy variable coefficient.

The variance equation including the dummy variable is written as:

$$
\begin{aligned}
& h_{t}=\omega+\alpha \varepsilon_{t-1}^{2}+\beta h_{t-1}+\delta D_{F} \\
& \operatorname{var}\left(\varepsilon_{t}\right)=\frac{\omega+\delta}{1-\alpha-\beta}
\end{aligned}
$$

where $\delta$ is the coefficient and $D_{F}$ is the dummy variable.

\section{Results and Discussion}

\subsection{Descriptive Analysis}

Table 1 gives the descriptive statistics for pre- and post-event individual shares. 
Table 1: Descriptive statistics

\begin{tabular}{|c|c|c|c|c|c|c|c|}
\hline Firm & & Mean & Median & SD & Skewness & Kurtosis & JB (p-value) \\
\hline \multirow[t]{2}{*}{ ENGRO } & Pre- & -0.001 & -0.002 & 0.029976 & -0.128 & 11.56474 & 0.000 \\
\hline & Post- & 0.000997 & 0.000614 & 0.024221 & -0.004 & 6.013720 & 0.000 \\
\hline \multirow[t]{2}{*}{ FABL } & Pre- & 0.002103 & 0.001458 & 0.027585 & -0.471 & 7.949325 & 0.000 \\
\hline & Post- & 0.001521 & 0.001356 & 0.029189 & -1.262 & 10.15042 & 0.000 \\
\hline \multirow[t]{2}{*}{ FFBL } & Pre- & 0.003289 & 0.000000 & 0.041945 & 0.345826 & 7.808736 & 0.000 \\
\hline & Post- & 0.001407 & 0.000000 & 0.025513 & 0.339097 & 4.134581 & 0.000 \\
\hline \multirow[t]{2}{*}{ FFC } & Pre- & 0.000 & 0.000000 & 0.027886 & -1.666 & 43.28937 & 0.000 \\
\hline & Post- & 0.002134 & 0.001447 & 0.020634 & -0.270 & 5.836772 & 0.000 \\
\hline \multirow[t]{2}{*}{ HUB } & Pre- & 0.000635 & 0.000000 & 0.030108 & 0.139531 & 6.856852 & 0.000 \\
\hline & Post- & 0.001552 & 0.001992 & 0.027161 & -0.744 & 9.792955 & 0.000 \\
\hline \multirow[t]{2}{*}{ KESC } & Pre- & 0.001173 & 0.000000 & 0.034128 & 1.215301 & 8.635981 & 0.000 \\
\hline & Post- & -0.002 & 0.000000 & 0.029418 & 0.819180 & 8.233262 & 0.000 \\
\hline \multirow[t]{2}{*}{ LUCKY } & Pre- & 0.002804 & 0.000000 & 0.028679 & 0.347713 & 3.876507 & 0.000002 \\
\hline & Post- & 0.002092 & 0.002304 & 0.027287 & -0.051 & 3.494917 & 0.069852 \\
\hline \multirow[t]{2}{*}{ MPLF } & Pre- & 0.003163 & 0.000000 & 0.032238 & 0.377267 & 3.523883 & 0.000152 \\
\hline & Post- & -0.001 & 0.000000 & 0.027643 & -0.069 & 3.532435 & 0.042739 \\
\hline \multirow[t]{2}{*}{ NML } & Pre- & 0.001104 & 0.000000 & 0.037895 & -0.988 & 12.99042 & 0.000 \\
\hline & Post- & 0.001639 & 0.000000 & 0.033319 & 0.335330 & 4.906277 & 0.000 \\
\hline \multirow[t]{2}{*}{ PIA } & Pre- & -0.002 & 0.000000 & 0.030568 & -0.061 & 4.965522 & 0.000 \\
\hline & Post- & 0.002502 & 0.000000 & 0.042873 & 0.974915 & 7.807721 & 0.000 \\
\hline \multirow[t]{2}{*}{ PIOC } & Pre- & 0.003450 & 0.000000 & 0.032683 & 0.104470 & 5.874602 & 0.000 \\
\hline & Post- & -0.002 & -0.002 & 0.029352 & -0.086 & 3.034602 & 0.723754 \\
\hline \multirow[t]{2}{*}{ PSO } & Pre- & 0.000637 & 0.000275 & 0.027285 & -0.123 & 10.57158 & 0.000 \\
\hline & Post- & 0.001362 & 0.000623 & 0.026797 & -0.095 & 5.823495 & 0.000 \\
\hline \multirow[t]{2}{*}{ PTCL } & Pre- & 0.000 & 0.000000 & 0.022892 & 0.125436 & 8.996783 & 0.000 \\
\hline & Post- & 0.001181 & 0.000000 & 0.024341 & -0.142 & 7.297403 & 0.000 \\
\hline \multirow[t]{2}{*}{ SNGP } & Pre- & 0.000303 & 0.000000 & 0.035134 & 0.280865 & 10.54835 & 0.000 \\
\hline & Post- & 0.002487 & 0.000000 & 0.029891 & -0.185 & 7.444145 & 0.000 \\
\hline \multirow[t]{2}{*}{ SSGP } & Pre- & 0.001921 & 0.000000 & 0.025665 & 0.237348 & 4.508559 & 0.000 \\
\hline & Post- & 0.000 & -0.002 & 0.025778 & 0.055356 & 3.496147 & 0.067755 \\
\hline \multirow[t]{2}{*}{ TELE } & Pre- & 0.000688 & 0.000000 & 0.030216 & 0.259989 & 4.657943 & 0.000 \\
\hline & Post- & -0.001 & -0.004 & 0.035922 & -0.886 & 14.22332 & 0.000 \\
\hline \multirow[t]{2}{*}{ ABL } & Pre- & -0.002 & -0.001 & 0.030599 & -0.280 & 4.571490 & 0.000 \\
\hline & Post- & 0.001883 & 0.000000 & 0.026991 & -0.066 & 4.254456 & 0.000 \\
\hline \multirow[t]{2}{*}{ NETSOL } & Pre- & -0.001 & -0.002 & 0.052528 & -13.231 & 250.2266 & 0.000 \\
\hline & Post- & -0.003 & -0.005 & 0.047136 & 0.745493 & 9.684422 & 0.000 \\
\hline \multirow[t]{2}{*}{ FCCL } & Pre- & -0.001 & 0.000000 & 0.026065 & -0.124 & 3.794509 & 0.000738 \\
\hline & Post- & -0.002 & -0.003 & 0.041262 & 0.012739 & 8.917209 & 0.000 \\
\hline \multirow[t]{2}{*}{ CSAP } & Pre- & 0.000109 & -0.001 & 0.028581 & -0.817 & 7.022855 & 0.000 \\
\hline & Post- & -0.002 & -0.003 & 0.034682 & -2.018 & 23.96737 & 0.000 \\
\hline \multirow[t]{2}{*}{ ATRL } & Pre- & 0.000624 & 0.000000 & 0.030562 & -0.820 & 7.005381 & 0.000 \\
\hline & Post- & -0.002 & 0.000 & 0.037650 & -1.764 & 14.90924 & 0.000 \\
\hline PRL & Pre- & -0.003 & -0.002 & 0.026916 & -0.224 & 4.243145 & 0.000 \\
\hline & Post- & 0.001151 & -0.001 & 0.028255 & 0.032965 & 2.669006 & 0.305289 \\
\hline PICT & Pre- & -0.002 & -0.001 & 0.030599 & -0.280 & 4.571490 & 0.000 \\
\hline & Post- & 0.001883 & 0.000000 & 0.026991 & -0.066 & 4.254456 & 0.000 \\
\hline WTL & Pre- & 0.000779 & -0.003 & 0.027665 & 0.308685 & 4.098218 & 0.000 \\
\hline & Post- & -0.002 & 0.000000 & 0.053642 & 0.112598 & 7.240552 & 0.000 \\
\hline
\end{tabular}

Source: Authors' calculations. 
We now look at the behavior of the data with respect to normality. In the majority of cases, the Jarque-Berra (JB) statistics show that the returns are not normal. In the post-event period, PIOC and PRL exhibit a normal distribution. All the shares show excess kurtosis; positive excess kurtosis indicates the leptokurtic behavior of returns. Negative skewness prevails in most cases. Financial data usually exhibit nonnormal behavior, which is also evident in this series. The ADF test is applied to check for a unit root (which would indicate that the series is nonstationary and could lead to spurious results). All the returns are, however, stationary at level (see Table 2).

Table 2: Stationary of returns

\begin{tabular}{lcccccc}
\hline & \multicolumn{2}{c}{ Full period } & \multicolumn{2}{c}{ Pre- } & \multicolumn{2}{c}{ Post- } \\
\cline { 2 - 7 } Firm & t-statistic & Prob. $^{*}$ & t-statistic & Prob. $^{*}$ & t-statistic & Prob. $^{*}$ \\
\hline ENGRO & -29.4449 & 0.0000 & -20.6093 & 0.0000 & -20.9949 & 0.0000 \\
FABL & -27.6713 & 0.0000 & -20.5057 & 0.0000 & -18.6759 & 0.0000 \\
FFBL & -33.0237 & 0.0000 & -24.2463 & 0.0000 & -21.5013 & 0.0000 \\
FFC & -33.7869 & 0.0000 & -25.3862 & 0.0000 & -21.4462 & 0.0000 \\
HUB & -30.2433 & 0.0000 & -21.2833 & 0.0000 & -21.3392 & 0.0000 \\
KESC & -25.0637 & 0.0000 & -17.3946 & 0.0000 & -18.3587 & 0.0000 \\
LUCKY & -29.1649 & 0.0000 & -21.1245 & 0.0000 & -19.9003 & 0.0000 \\
MPLF & -29.709 & 0.0000 & -21.2602 & 0.0000 & -20.7242 & 0.0000 \\
NML & -29.981 & 0.0000 & -22.0648 & 0.0000 & -19.9915 & 0.0000 \\
PIA & -33.8942 & 0.0000 & -25.7774 & 0.0000 & -23.2023 & 0.0000 \\
PIOC & -26.6361 & 0.0000 & -19.2042 & 0.0000 & -18.5536 & 0.0000 \\
PSO & -31.438 & 0.0000 & -21.7735 & 0.0000 & -22.6163 & 0.0000 \\
PTCL & -32.0945 & 0.0000 & -23.7087 & 0.0000 & -21.765 & 0.0000 \\
SNGP & -31.9307 & 0.0000 & -22.0872 & 0.0000 & -23.2462 & 0.0000 \\
SSGP & -26.737 & 0.0000 & -18.8382 & 0.0000 & -18.9401 & 0.0000 \\
TELE & -28.2739 & 0.0000 & -20.6682 & 0.0000 & -19.4902 & 0.0000 \\
ABL & -26.8719 & 0.0000 & -18.0994 & 0.0000 & -20.2883 & 0.0000 \\
NETSOL & -25.5238 & 0.0000 & -18.6514 & 0.0000 & -17.5892 & 0.0000 \\
FCCL & -25.0909 & 0.0000 & -20.1877 & 0.0000 & -18.7955 & 0.0000 \\
CSAP & -25.9801 & 0.0000 & -20.1524 & 0.0000 & -17.1362 & 0.0000 \\
ATRL & -23.5107 & 0.0000 & -18.7351 & 0.0000 & -15.2765 & 0.0000 \\
PRL & -23.4802 & 0.0000 & -17.4566 & 0.0000 & -15.8312 & 0.0000 \\
PICT & -26.8719 & 0.0000 & -18.0994 & 0.0000 & -20.2883 & 0.0000 \\
WTL & -32.3585 & 0.0000 & -22.1253 & 0.0000 & -23.0351 & 0.0000 \\
\hline
\end{tabular}

Source: Authors' calculations.

To determine the conditional volatility, we apply the ARCH LM test to detect the ARCH effect (Table 3). It is necessary for the series to exhibit an ARCH effect, so that GARCH $(1,1)$ is applied. The data comprises 41 shares over two years with pre- and post-event data on SSF firms from 1 July 2001 to 31 December 2010. Out of the 41 shares, 27 
exhibited the ARCH effect but three companies were excluded because of GARCH assumption violations. The final sample consists of 24 shares.

Table 3: Pre-diagnostic ARCH LM test

\begin{tabular}{llrl}
\hline No. & Name & F-statistic & Prob. \\
\hline 1 & ENGRO & 28.76 & 0.00 \\
2 & FABL & 4.11 & 0.04 \\
3 & FFBL & 14.12 & 0.00 \\
4 & FFC & 145.90 & 0.00 \\
5 & HUB & 88.88 & 0.00 \\
6 & KESC & 100.90 & 0.00 \\
7 & LUCKY & 35.06 & 0.00 \\
8 & MPLF & 27.01 & 0.00 \\
9 & NML & 40.61 & 0.00 \\
10 & PIA & 25.43 & 0.00 \\
11 & PIOC & 9.74 & 0.00 \\
12 & PSO & 17.90 & 0.00 \\
13 & PTCL & 27.24 & 0.00 \\
14 & SNGP & 4.24 & 0.04 \\
15 & SSGP & 91.37 & 0.00 \\
16 & TELE & 3.33 & 0.07 \\
17 & ABL & 5.31 & 0.02 \\
18 & NETSOL & 7.17 & 0.01 \\
19 & FCCL & 122.85 & 0.00 \\
20 & CSAP & 6.20 & 0.01 \\
21 & ATRL & 150.87 & 0.00 \\
22 & PRL & 66.36 & 0.00 \\
23 & PICT & 20.25 & 0.00 \\
24 & WTL & 174.51 & 0.00 \\
\hline & & &
\end{tabular}

Source: Authors' calculations. variance.

Table 4 gives the results of the F-test, showing differences in 
Table 4: F-test for differences in variance

\begin{tabular}{|c|c|c|c|c|}
\hline \multirow[b]{2}{*}{ Name } & \multicolumn{3}{|c|}{ Change in standard deviation } & \multirow[b]{2}{*}{ P-value } \\
\hline & Pre-SSF & Post-SSF & Change & \\
\hline ENGRO & 0.00090 & 0.00059 & -0.00031 & 0.0000 \\
\hline FABL & 0.00076 & 0.00085 & 0.00009 & 0.1035 \\
\hline FFBL & 0.00176 & 0.00065 & -0.00111 & 0.0000 \\
\hline FFC & 0.00078 & 0.00043 & -0.00035 & 0.0000 \\
\hline HUB & 0.00091 & 0.00074 & -0.00017 & 0.0108 \\
\hline KESC & 0.00116 & 0.00087 & -0.00030 & 0.0005 \\
\hline LUCKY & 0.00082 & 0.00074 & -0.00008 & 0.1333 \\
\hline MPLF & 0.00104 & 0.00076 & -0.00028 & 0.0003 \\
\hline NML & 0.00144 & 0.00111 & -0.00033 & 0.0021 \\
\hline PIA & 0.00093 & 0.00184 & 0.00090 & 0.0000 \\
\hline PIOC & 0.00107 & 0.00086 & -0.00021 & 0.0083 \\
\hline PSO & 0.00074 & 0.00072 & -0.00003 & 0.3437 \\
\hline PTCL & 0.00052 & 0.00059 & 0.00007 & 0.0853 \\
\hline SNGP & 0.00123 & 0.00089 & -0.00034 & 0.0002 \\
\hline SSGP & 0.00066 & 0.00066 & 0.00001 & 0.4610 \\
\hline TELE & 0.00091 & 0.00129 & 0.00038 & 0.0001 \\
\hline $\mathrm{ABL}$ & 0.00094 & 0.00073 & -0.00021 & 0.0026 \\
\hline NETSOL & 0.00096 & 0.00120 & 0.00024 & 0.0059 \\
\hline FCCL & 0.00068 & 0.00170 & 0.00102 & 0.0000 \\
\hline CSAP & 0.00082 & 0.00120 & 0.00039 & 0.0000 \\
\hline ATRL & 0.00093 & 0.00142 & 0.00048 & 0.0000 \\
\hline PRL & 0.00072 & 0.00080 & 0.00007 & 0.1394 \\
\hline PICT & 0.00094 & 0.00073 & -0.00021 & 0.0026 \\
\hline \multirow[t]{5}{*}{ WTL } & 0.00077 & 0.00288 & 0.00211 & 0.0000 \\
\hline & Decrease in SD & & Increase in SD & \\
\hline & 13 & & 11 & \\
\hline & $\mathrm{s}$ & ns & $\mathrm{s}$ & ns \\
\hline & 11 & 2 & 8 & 3 \\
\hline
\end{tabular}

Note: $\mathrm{s}=$ significant, $\mathrm{ns}=$ not significant.

Source: Authors' calculations. 
Figure 1: Changes in volatility
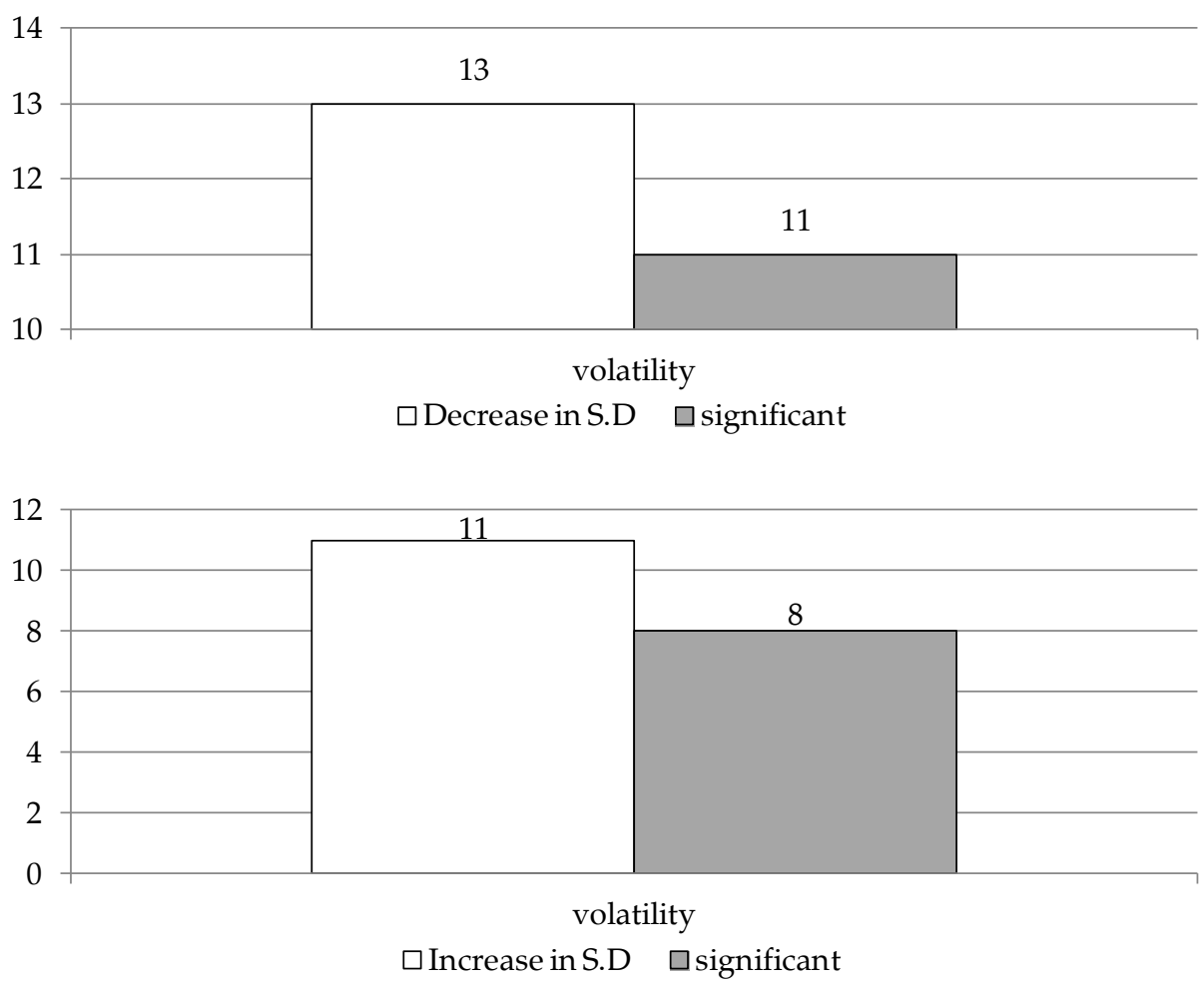

\subsection{F-test Analysis}

The results indicate a greater decrease in volatility after SSF trading, which reflects the stabilizing effect of futures trading. Table 5 shows individual companies' response to futures trading. These are categorized into five different patterns and interpreted. Table 6 summarizes the GARCH $(1,1)$ analysis for our sample. 


\section{Table 5: Individual firms' response to SSF trading}

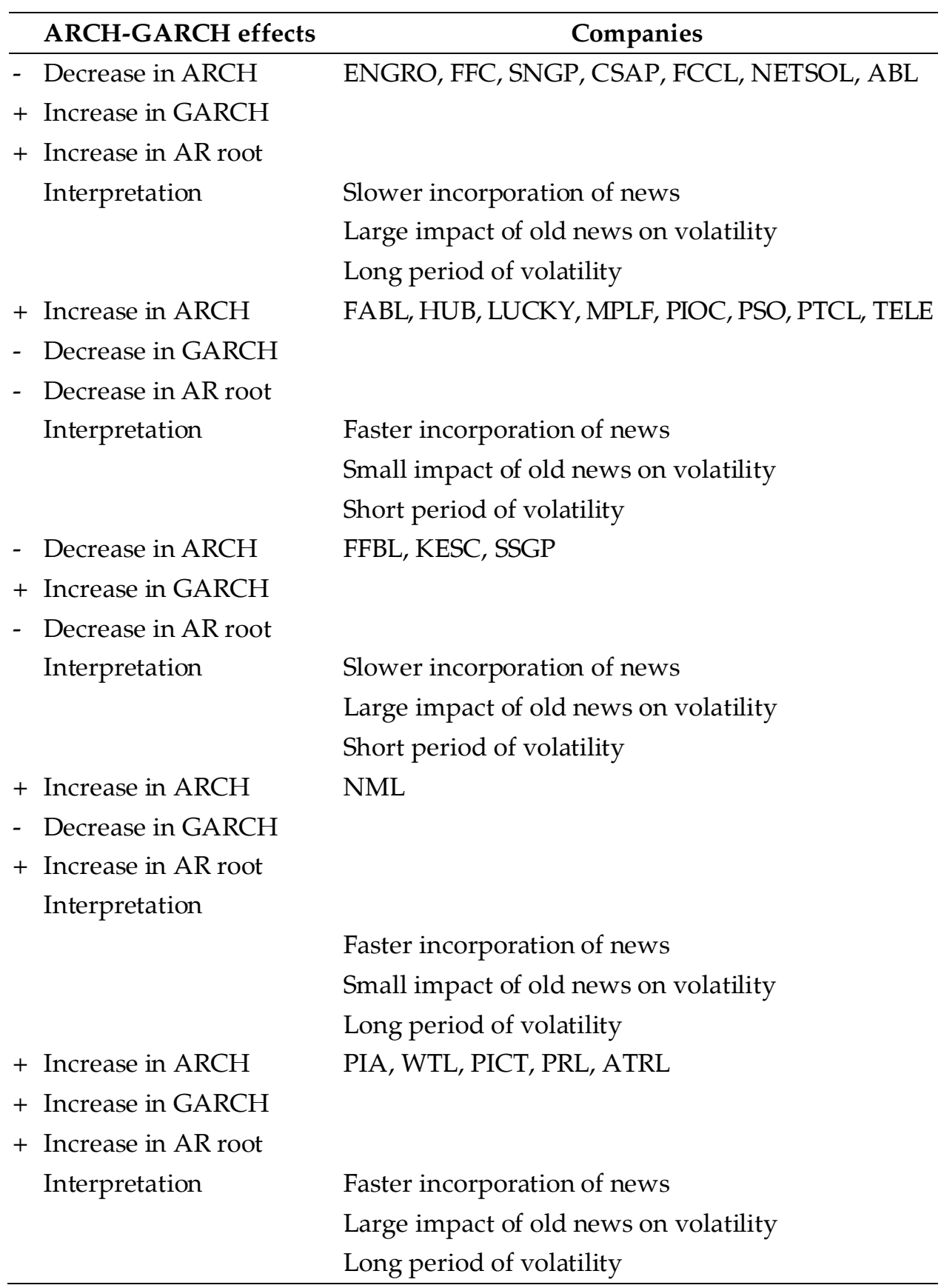

Source: Authors' calculations. 
Table 6: Summary of GARCH $(1,1)$ analysis

\begin{tabular}{|c|c|c|c|c|c|}
\hline No. & SSF & DF & $\mathrm{ARCH}$ & GARCH & AR root \\
\hline 1 & ENGRO & - & - & + & + \\
\hline 2 & FABL & - & + & - & - \\
\hline 3 & FFBL & - & - & + & - \\
\hline 4 & FFC & - & - & + & + \\
\hline 5 & HUB & - & + & - & - \\
\hline 6 & KESC & - & - & + & - \\
\hline 7 & LUCKY & - & + & - & - \\
\hline 8 & MPLF & - & + & - & - \\
\hline 9 & NML & - & + & - & + \\
\hline 10 & PIA & + & + & + & + \\
\hline 11 & PIOC & - & + & - & - \\
\hline 12 & PSO & + & + & - & - \\
\hline 13 & PTCL & + & + & - & - \\
\hline 14 & SNGP & - & - & + & + \\
\hline 15 & SSGP & - & - & + & - \\
\hline 16 & TELE & + & + & - & - \\
\hline 17 & WTL & + & + & + & + \\
\hline 18 & PICT & - & + & + & + \\
\hline 19 & PRL & - & + & + & + \\
\hline 20 & ATRL & - & + & + & + \\
\hline 21 & CSAP & + & - & + & + \\
\hline 22 & FCCL & + & - & + & + \\
\hline 23 & NETSOL & + & - & + & + \\
\hline 24 & ABL & - & - & + & + \\
\hline
\end{tabular}

\begin{tabular}{|c|c|c|c|c|c|c|c|c|c|c|c|c|}
\hline \multicolumn{4}{|c|}{ Spot volatility } & \multicolumn{4}{|c|}{ Dissemination rate } & \multicolumn{3}{|c|}{ Long-term impact } & \multicolumn{2}{|c|}{ Persistence of shocks } \\
\hline \multicolumn{2}{|c|}{ Decrease } & \multicolumn{2}{|c|}{ Increase } & \multicolumn{2}{|c|}{ Decrease } & \multicolumn{2}{|c|}{ Increase } & \multicolumn{2}{|c|}{ Decrease } & Increase & \multirow{2}{*}{ Decrease } & \multirow{2}{*}{$\begin{array}{c}\text { Increase } \\
13\end{array}$} \\
\hline \multicolumn{2}{|c|}{16} & \multicolumn{2}{|c|}{8} & \multicolumn{2}{|c|}{10} & \multicolumn{2}{|c|}{14} & \multicolumn{2}{|c|}{9} & 15 & & \\
\hline $\mathrm{s}$ & ns & $\mathrm{s}$ & ns & $\mathrm{s}$ & ns & $\mathrm{s}$ & ns & $\mathrm{s}$ & ns & ns & & \\
\hline 3 & 13 & 5 & 3 & 9 & 1 & 14 & - & 8 & 1 & 13 & & \\
\hline
\end{tabular}

Note: $\mathrm{s}=$ significant, $\mathrm{ns}=$ not significant.

Source: Authors' calculations. 
Figure 2: Long-term impact, persistence, and volatility
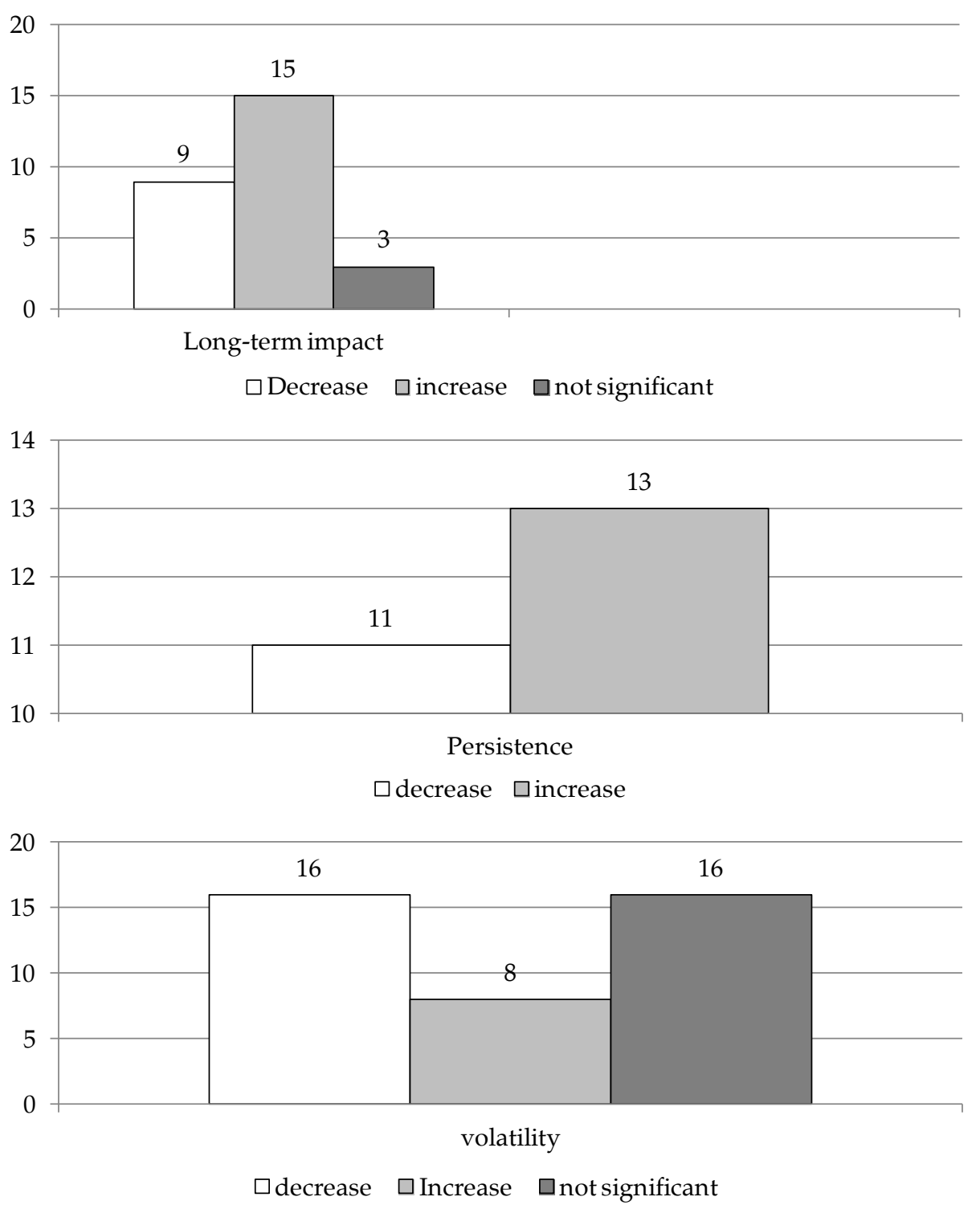

\subsection{GARCH (1,1) Analysis}

The majority of firms experienced a statistically significant decrease in volatility, with only five shares showing a statistically significant increase. Fourteen shares showed a significant increase in the rate of news incorporation, compared to nine shares that showed a significant decrease in the dissemination rate. Similarly, there was a significant increase in the 
long-term impact of 13 shares with eight showing a decrease in the impact of old news. The increased incorporation of news in prices and the longterm impact of old news led to an increase in persistence of the shock effect for 13 shares. The ARCH LM test is reapplied to check the remaining $\mathrm{ARCH}$ effect. We find that, for all the shares, no ARCH effect is left over.

Table 7: Post-diagnostics for ARCH LM test

\begin{tabular}{lllllll}
\hline & \multicolumn{2}{c}{ Full } & \multicolumn{2}{c}{ Pre- } & \multicolumn{2}{c}{ Post- } \\
\cline { 2 - 7 } Name & F-statistic & Prob. $^{*}$ & F-statistic & Prob. $^{*}$ & F-statistic & Prob.* $^{*}$ \\
\hline ENGRO & 0.28363 & 0.5945 & 0.101817 & 0.7498 & 0.270438 & 0.6033 \\
FABL & $8.12 \mathrm{E}-05$ & 0.9928 & 0.056489 & 0.8122 & 0.270438 & 0.6033 \\
FFBL & 0.500265 & 0.4795 & 0.714687 & 0.3983 & 0.043029 & 0.8358 \\
FFC & 0.011526 & 0.9145 & 0.002426 & 0.9607 & 0.145052 & 0.7035 \\
HUB & 0.092346 & 0.7613 & 0.110351 & 0.7399 & 0.132487 & 0.716 \\
KESC & 0.297581 & 0.5855 & 0.387924 & 0.5337 & 0.005348 & 0.9417 \\
LUCKY & 0.018597 & 0.8916 & 0.12658 & 0.7222 & 0.069259 & 0.7925 \\
MPLF & 0.038806 & 0.8439 & 0.006397 & 0.9363 & 0.059263 & 0.8078 \\
NML & 2.27312 & 0.132 & 1.121221 & 0.2902 & 1.030216 & 0.3106 \\
PIA & 0.825346 & 0.3638 & 0.377225 & 0.5394 & 0.365154 & 0.5459 \\
PIOC & 0.020692 & 0.8856 & 0.011685 & 0.914 & 0.16592 & 0.6839 \\
PSO & 0.009179 & 0.9237 & 0.068158 & 0.7941 & 0.460655 & 0.4976 \\
PTCL & 0.001008 & 0.9747 & 0.001533 & 0.9688 & 0.002449 & 0.9605 \\
SNGP & 0.60092 & 0.4384 & 0.720607 & 0.3964 & 0.012194 & 0.9121 \\
SSGP & 0.054115 & 0.8161 & 0.073785 & 0.786 & 0.029758 & 0.8631 \\
TELE & 0.112181 & 0.7377 & $1.17 \mathrm{E}-05$ & 0.9973 & 0.051665 & 0.8203 \\
WTL & 0.862318 & 0.3533 & 0.116504 & 0.733 & 0.742151 & 0.3894 \\
PICT & 0.521795 & 0.4702 & 0.498874 & 0.4803 & 0.00585 & 0.9391 \\
PRL & 0.006386 & 0.9363 & 0.047317 & 0.8279 & 1.114346 & 0.2917 \\
ATRL & 0.000899 & 0.9761 & 0.088883 & 0.7657 & 0.000747 & 0.9782 \\
CSAP & 0.05644 & 0.8123 & 0.292578 & 0.5888 & 0.025685 & 0.8727 \\
FCCL & 2.606255 & 0.1068 & 0.140523 & 0.7079 & 10.10767 & 0.1600 \\
NETSOL & 0.008391 & 0.927 & 0.076264 & 0.7825 & 0.005595 & 0.9404 \\
ABL & 1.904208 & 0.1679 & 0.128298 & 0.7204 & 1.465631 & 0.2266 \\
\hline & & & & & &
\end{tabular}

Source: Authors' calculations.

\subsection{Discussion}

This study has applied traditional measures of volatility (F-test) as well as econometric techniques (GARCH modeling). Both analyses showed 
that, in the majority of cases, futures trading had a mixed effect on volatility. One can, therefore, reasonably conclude that SSF trading leads to lower spot market volatility. The results are contrary to the complete markets theory, the diminishing short sales restriction theory, and the improved information environment hypothesis, which state that a decrease in volatility follows derivatives trading.

Our findings are in line with Chau et al. (2005) and Hung et al. (2003). With respect to changes in the structure of volatility, the increased rate of news transmission into share prices is followed by long periods of excessive price movement, leading to an extended period of volatility. Futures trading thus attracts both informed and uninformed traders. The faster incorporation of news in share prices attracts informed traders, while the larger contribution of old news to volatility shows that uninformed traders are attracted to the futures market. The increase in the ARCH and GARCH terms results in the extended period of volatility (persistence of shocks effect).

\section{Conclusion and Recommendations}

SSFs have a mixed effect with respect to the level of volatility. SSF contracts alter the structure of volatility with an increase in the $\mathrm{ARCH}$ term, GARCH term, and autoregressive term. The increase in the ARCH and GARCH terms suggests that SSFs attract both informed and uninformed investors, which leads to an increase in the persistence of shocks effect. Consequently, this study is in line with most existing studies, which also report no effect. The persistency of shocks effect implies that strict regulations are needed with respect to futures trading.

This study could be extended by analyzing the impacts of "good" and "bad" news on volatility post-stock futures trading. Asymmetric models such as T-GARCH and E-GARCH could be applied. A sector-wise analysis could also be conducted to analyze the effect of stock futures on the underlying spot prices of the specific sector. 


\section{References}

Ahmad, H., Shah, A. Z., \& Shah, I. (2010). Impact of futures trading on spot-price volatility: Evidence from Pakistan. International Research Journal of Finance and Economics, 59, 146-164.

Aitken, M., \& Segara, R. (2005). Impact of warrant introduction on the behavior of underlying stocks: Australian evidence. Accounting and Finance, 45(1), 127-144.

Ang, J., \& Cheng, Y. (2005). Financial innovations and market efficiency: The case of single-stock futures. Journal of Applied Finance, 15(1), 38-51.

Arditti, F., \& John, K. (1980). Spanning the state space with options. Journal of Financial and Quantitative Analysis, 15, 1-9.

Bae, S. C., Kwon, T. H., \& Park, J. W. (2004). Futures trading, spot market volatility, and market efficiency: The case of the Korean index futures markets. Journal of Futures Markets, 24(12), 1195-1228.

Bollerslev, T. (1986). Generalized autoregressive conditional heteroskedasticity. Journal of Econometrics, 31, 307-327.

Bologna, P., \& Cavallo, L. (2002). Does the introduction of stock index futures effectively reduce stock market volatility? Is the futures effect immediate? Evidence from the Italian stock exchange using GARCH. Applied Financial Economics, 12, 183-192.

Butterworth, D. (2000). The impact of futures trading on underlying stock index volatility: The case of the FTSE Mid-250 contract. Applied Economics Letters, 7(7), 439-442.

Chatrath, A., Ramchander, S., \& Song, F. (1995). Does options trading lead to greater cash market volatility? Journal of Futures Markets, 15(7), 785-803.

Chau, F., Holmes, P., \& Paudyal, K. (2005). The impact of single-stock futures on feedback trading and the market dynamics of the cash market (Working Paper No. 05/12). Durham, UK: University of Durham.

Clarke, M., Gannon, G., \& Vinning, R. (2007). The impact of warrant introduction: Australian experience (Working Paper No. 2007/11). Melbourne, Australia: Deakin University. 
Darrat, A. F., \& Rahman, S. (1995). Has futures trading activity caused stock price volatility? Journal of Futures Markets, 15(5), 537-557.

De Beer, J. (2008). The impact of single-stock futures on South African equity market. Master's thesis, University of South Africa, Pretoria.

Dennis, S. A., \& Sim, A. B. (1999). Share price volatility with the introduction of single-share futures on the Sydney Futures Exchange. International Review of Financial Analysis, 8(2), 153-163.

Detemple, J., \& Selden, L. (1991). A general equilibrium analysis of option and stock market interactions. International Economic Review, 32, 279-303.

Drimbetas, E., Sariannidis, N., \& Porfiris, N. (2007). The effect of derivatives trading on volatility of the underlying asset: Evidence from the Greek stock market. Applied Financial Economics, 17(2), 139-148.

Elfakhani, S., \& Chaudhury, M. (1995). The volatility effect of option listing: Some Canadian evidence. Quarterly Review of Economics and Finance, 35, 97-116.

Engle, R. F. (1982). Autoregressive conditional heteroskedasticity with estimates of the variance of UK inflation. Econometrica, 50, 987-1007.

Engle, R. F. (1993). Statistical models for financial volatility. Financial Analysts Journal, 49(1), 72-78.

Engle, R. F. (2001). GARCH 101: The use of ARCH/GARCH models in applied econometrics. Journal of Economic Perspectives, 15(4), 157-168.

Faff, R., \& Hillier, D. (2005). Complete markets, informed trading and equity option introductions. Journal of Banking and Finance, 29, 1359-1384.

Figlewski, S., \& Webb, G. P. (1993). Options, short sales, and market completeness. Journal of Finance, 48, 761-777.

Hung, M. W., Lee, C. F., \& So, L. C. (2003). Impact of foreign-listed singlestock futures on the domestic underlying stock markets. Applied Economics Letters, 10(9), 567-574.

Jones, T., \& Brooks, R. (2005). An analysis of single-stock futures trading in the US. Financial Services Review, 14, 85-95. 
Khan, S. (2006). Role of futures market on volatility and price discovery of the spot market: Evidence from Pakistan's stock market. Lahore Journal of Economics, 11(2), 107-121.

Khan, S., \& Hijazi, S. T. (2009). Single-stock futures trading and stock price volatility: Empirical analysis. Pakistan Development Review, 48(4), 553-563.

Khan, S., Shah, A., \& Abbas, Z. (2011). Impact of single-stock futures trading on stock price volatility of underlying stocks: Empirical evidence from Pakistan's stock market. Journal of Basic and Applied Scientific Research, 1(11), 2000-2008.

Kruger, W. K. (2000). Equity index futures contracts and share price volatility: A South African perspective (Mimeo). Potchefstroom, South Africa: Potchefstroom University for Christian Higher Education.

Kumar, K. K., \& Mukhopadhyay, C. (2004). Impact of futures introduction on underlying NSE Nifty volatility. In N. Swain, D. K. Malhotra, \& B. Roy (Eds.), Proceedings of the International Conference 2003 on Business and Finance (vol. 3, pp. 326-341). Hyderabad, India: ICFAI University Press.

Lee, C. I., \& Tong, H. C. (1998). Stock futures: The effects of their trading on the underlying stocks in Australia. Journal of Multinational Financial Management, 8(2-3), 285-301.

Mazouz, K. (2004). The effect of CBOE option listing on the volatility of NYSE traded stocks: A time-varying variance approach. Journal of Empirical Finance, 11(5), 695-708.

Mazouz, K., \& Bowe, M. (2006). The volatility effect of futures trading: Evidence from LSE traded stocks listed as individual equity futures contracts on LIFFE. International Review of Financial Analysis, 15(1), 1-20.

McKenzie, M. D., Brailsford, T. J., \& Faff, R. W. (2001). New insights into the impact of the introduction of futures trading on stock price volatility. Journal of Futures Markets, 21(3), 237-255.

Miller, E. M. (1977). Risk, uncertainty, and divergence of opinion. Journal of Finance, 32(4), 1151-1168. 
Mukherjee, A. (2006). Why India is crazy about single-stock futures. Retrieved from http://www.bloomberg.com/apps/news?pid= newsarchive\&sid=aZqb_UbMh388.

Oehley, D. J. (1995). The effect of the introduction of index future trading on underlying index volatility (Mimeo). Johannesburg, South Africa: University of the Witwatersrand.

Parsons, J. (1998). Futures trading and cash market volatility (Mimeo). Stellenbosch, South Africa: University of Stellenbosch.

Paulden, P. (2005). Future shock. Institutional Investor, 39(12), 76-80.

Peat, M., \& McCorry, M. (1997). Individual-share futures contracts: The economic impact of their introduction on the underlying equity market (Working Paper No. 74). Sydney, Australia: University of Technology.

Raul, R. K. (2004). Stock futures in derivative family (Mimeo). Kolkata, India: Institute of Cost Accountants of India.

Robbani, M. G., \& Bhuyan, R. (2005). Futures trading activity and stock price volatility. Derivatives Use, Trading and Regulation, 11(3), 246-260.

Ross, S. (1977). Options and efficiency. Quarterly Journal of Economics, 90, 75-89.

Smit, E. M., \& Nienaber, H. (1997). Futures trading activity and share price volatility in South Africa. Investment Analysts Journal, 44, 51-59.

Strong, R. A. (2005). Derivatives: An introduction (2nd ed.). Mason, OH: Thomson, South-Western.

Swart, A. (1998). The impact of share index futures trading on the volatility and liquidity of the underlying assets on the Johannesburg Stock Exchange (Mimeo). South Africa: University of Cape Town.

Vanden Baviere, L., \& De Villiers, J. U. (1997). Share volatility after the introduction of index futures. Investment Analysts Journal, 45, 9-15. 